\title{
On the Problems of Introducing Innovations in The Process of Life Safety Training in A Higher Education Institution
}

\author{
Mikhail Yuryevich Zelenkov ${ }^{1 *}$, Elena Mikhailovna Priorova ${ }^{2}$, Vladimir Vladimirovich \\ Leonov $^{2}$, Irina Vladimirovna Khomutova ${ }^{3}$, and German Evgenievich Priorov ${ }^{2}$ \\ ${ }^{1}$ Bauman Moscow State Technical University, Moscow, Russia \\ ${ }^{2}$ Moscow Region State University, Department of Social Security, Russia \\ ${ }^{3}$ Moscow Region State University, Department of Security Training Methodology, Russia
}

\begin{abstract}
The object of this study is the issue of introducing innovations into the process of preparing students of a higher education institution in the subject "Life Safety". The authors set a goal to open and characterize the fundamental issues associated with the introduction of innovations in the educational process of a university in a particular subject based on a comprehensive systematic analysis of the process of preparing students in universities, as well as basic regulatory legal documents in the field of education and basic professional educational programs and curricula. Moreover, the authors rely not only on approaches and conclusions based on solidarity, but also alternative theoretical ones. The results obtained during the study made it possible to determine ways to solve the issues associated with the correlation of innovative approaches with the subject "Life Safety". The novelty of the study and its results are determined by the original approach to identifying the characteristic features of innovations in the educational process and studying the systemic links between innovative forms, methods of the educational process and the content of the subject.
\end{abstract}

\section{Introduction}

The introduction in 1991 of the subject "Life Safety" as an obligatory part of the educational process of a university has become an important milestone in the development of a promising sovereign field of scientific knowledge [1]. However, studies have shown that between the content of the pedagogical process at the university and real practice, there is an elusive and constant abyss [2-5] The issue lies in the fact that today human and social life safety training is not only a fundamental part of the training of a professional specialist, but also a strategic direction of a university. Essentially, in the process of teaching this subject, the formation of a person's worldview takes place, who can find a way out of force majeure situations, which nowadays happen more often. At the same time, the lack of innovative approaches does not allow reaching the level of training of a university graduate that is adequate to the present. K. Turvey and N. Pachler [6] note that new critical and theoretical approaches create the

* Corresponding author: mz60@mail.ru 
ability to connect research and practice in the field of educational technologies. Based on this, the purpose of the study is the identification and justification of innovative ways that can lead to an increase in the effectiveness of teaching the subject "Life Safety".

\section{Methods}

The methodological base of the study was a system-integrated approach, which made it possible to identify and justify the need to introduce innovations in the educational process in the subject "Life Safety". The epistemological potential of statistical and sociological methods of quantitative research made it possible to interpret the results of scientific research on the analyzed subject correctly.

\section{Results}

What are the ways to solve these issues?

First, it is the introduction of a set of comprehensive measures in the educational process aimed at enhancing the cognitive activity of students. This should include modern forms of training, latest educational material base, a balanced budget for lectures and practical classes, as well as the prevalence of the possibility for students to manifest their abilities and initiatives in the classroom. An example is an educational and methodological package created at the Faculty of Life Safety of Moscow Region State University, which allows students to gain theoretical knowledge, develop their pedagogical abilities and master the methods of teaching life safety used in the educational process.

Second, it is the reengineering of a scientific school in this field of knowledge, aimed at improving the methodological support of the educational process to form the student's relevant competencies based on a personality-oriented approach. It should be recognized that only clearly expressed interest of a student, their curiosity and initiative can increase the efficiency of training highly qualified specialists. Such a method as "teaching to the test" in the field of ensuring the safety of life of an individual, society and the state is finally a thing of the past.

Third, in universities, it is necessary to develop models for training a future specialist in life safety issues, based on the specific requirements of the future professional activity of a graduate as well as the current and future state of the political and socioeconomic situation. The main objective of these models is the formation of the student's competencies that can provide them with an effective counteraction to modern dangers and threats to life.

Fourth, one should pay attention to the level of training of a teacher of the subject "Life Safety". For in a certain sense they are a key figure; they have a strategic role in the development of a student's worldview. It is well known that a student transfers their attitude to a teacher to the studied subject. "The authority of a teacher and the established reputation grows extremely slowly, and one can lose them in a short time. During the school year, a student spends $25 \%$ of the time communicating with teachers. With the direct participation of teachers, a student receives about $15-20 \%$ of the skills. As the results of sociological studies show, more than $60 \%$ of students take university teachers as role models".

Fifth, the existing system for monitoring the quality of knowledge and skills of trainees needs innovation. Usually, one determines the level of knowledge of a student by questioning them on a certain subject or just by giving them a test. The more knowledge and practical skills they demonstrate, the higher the level of their training. However, practice shows that this is very often not true. Therefore, it is necessary to shift the emphasis of the educational process from the monitoring to the formation of specific attitudes in a student, the disclosure of characteristics and capabilities of the information environment that supports obtaining the 
necessary knowledge in the process of self-mastering the content of the subject and the selection of correct methods of working with the content in accordance with the objectives of a lesson, etc.

\section{Discussion}

The analysis and the results show that the first quarter of the 21 st century in the field of training students on the basics of life safety was marked by a certain crisis of the pedagogical model that prevailed earlier in higher education. This is due to the fact that the higher education received today is less and less adequate to the conditions of political and socioeconomic reality with its characteristic increase in the threats to the life of the individual, society and the state, the source of which are globalization, terrorism, natural disasters, uncontrolled migration, and the strengthening of destructive elements in intercultural dialogue, etc [7-11]. Although the gap between theory and practice is an urgent and often insurmountable issue, there are several innovations, the implementation of which, from our point of view, is optimistic. However, it is important to emphasize that not all innovations introduced into the modern educational process are improvements. We agree with K. Zierer [12], who believes that professionalization in training today is carried out according to two different approaches: the "competency-based approach" and the "critical reflection approach". The issue here is the following.

First, to distinguish between changes and improvements in training, it is necessary to explain clearly what a modern specialist in one field or another should know and do. The emotional and cognitive benefits of creativity and mindfulness writes N. Hensley [13], are well documented in the learning process. However, innovation is an improvement if there is evidence that it will be more effective to support the progress of students in achieving their learning objectives than its typical forms. Innovation, as a rule, is conceptualized on the inclusion of both the creation of creative ideas and their implementation. Creativity is often understood not only as the first step of innovation, but also as something that accompanies almost the entire process of introducing innovations [14-16]. At the same time, it should be recognized that this view has an administrative dimension, since there are often contradictions between the views of scientists and officials from education in this regard;

Second, innovations introduced into the pedagogical process of studying one subject will not always give a clear improvement in relation to another subject. For example, the process of teaching history or philosophy and life safety is not correlated in forms and methods, especially in the field of control of acquired knowledge and skills. It is worth noting that D. Schwartz, D. Bransford and D. Sears warned about this [17];

Third, innovation is a process that is not stagnant, but dynamic; it must be monitored, analyzed and reviewed. Here again, dependence on the taught subject comes to the fore. The truth of this judgment lies in the fact that for some subjects the introduction of innovations gives a positive effect for a long time, and for others - this action can only have short-term success;

Fourth, innovation in the implementation process must necessarily adapt to the conditions of each university, teacher and students, with an emphasis on the specialty and direction of training, as well as on local and regional conditions. The ability of teachers to flexibly use their personal qualities, as noted by I. Männikkö and J. Husu [18], is important in complex classroom situations for a deeper understanding and development of teaching. Introducing innovations in one educational stream can be a difficult task, but it is even more demanding when the issue concerns the entire university. Moreover, it becomes exponentially more complex when the expansion of innovation is aimed at many universities, districts, regions or even countries. Practice shows that the introduction of innovative approaches to learning does not work when this process is implemented based on an administrative rather than 
pedagogical point of view on the logic of acquiring trainees the necessary knowledge, skills and abilities.

The introduction of innovations in the training process for a specific subject also requires an answer to the following questions:

To what extent can educational resources lead to effective changes in the everyday pedagogical process?

How to strengthen effectively the support of professional development for both students and teachers?

What are the critical aspects of the systemic context that affect the widespread adoption of innovations, and what are the key characteristics of contexts that support teachers constantly improving their pedagogical activities?

Which innovations are most effective when they are aimed at large-scale improvement of the quality of the educational process, and which are effective in a specific field of knowledge?

The introduction of FSES HE (Federal State Educational Standard of Higher Education) generations $3+$ and $3++$ in the 2010 s gave the university administration and teachers great academic freedom. Today, the content of the subject is determined by competencies and the specific result of their development, and not by didactic units. However, many FSES HE competencies have wide boundaries. For example, GE-8 (General Competency) in the FSES HE 44.03.01 for the subject "Life Safety": "able to create and maintain safe living conditions, including in emergency situations".

Under these conditions, it is alarming that a teacher should design the content of the course so that a student can master the maximum range of knowledge about modern life threats and understand the ways to parry them. However, the content of the course, correct to the situation, can only be created by a teacher who themself is at the forefront of professional activity and had practical experience in the field of life safety. If we assume that for one reason or another, a teacher has only theoretical knowledge (graduate of the university) and does not have practical experience then what kind of work program for the subject can they draw up and what requirements is a student entitled to present? Therefore, for teachers of the subject "Life Safety", in which the issue of preserving human life is studied, an innovative approach to the very concept of a professional teacher is necessary. It is important to consider not only theoretical knowledge of a subject, but also practical experience, allowing through contact with a student help them acquire the necessary skills in their later life.

There is another feature of the modern educational process, which is the fact that the work on introducing innovations takes place directly in the course of its dynamics. This "restructuring on the march" creates additional difficulties, and significant ones, imposing increased responsibility on both those who make decisions and those who implement them. It must be acknowledged that there are more unresolved issues than resolved ones in the process of forming students' knowledge and skills in the field of life safety today.

\section{Conclusion}

These ways to solve the issues of introducing innovations will allow, in our opinion, to reorient the process of preparation for the subject "Life Safety" from the traditional goal the simple assimilation of knowledge, skills and abilities, to the development of the student's internal and external self-organization and will provide them with the potential to create an individual trajectory of their development. Although these initiatives, when implemented, will make a significant contribution to the educational process, we still have much to learn about how to support their implementation on a large scale. Not only that this type of work is often regarded as secondary to research issues in the field of pedagogy, but also that the 
implementation of large-scale implementation projects is very expensive in terms of time and finances, not to mention the process of monitoring their impact.

\section{References}

1. S.V. Abramova. Theory and methodology of training of life safety activities (Izd-vo SakhGU, Yuzhno-Sakhalinsk, 2012)

2. M.YU. Zelenkov, V.Ye. Demyanenko, Innovatsii i investitsii 12, 2-5 (2014)

3. B. Stanley, G.K. Brown, Cogn. Behav. Pract. 19(2), 256-264 (2012).

4. D.J. Kayman, M.F. Goldstein, L. Dixon, M. Goodman, Crisis, 36 (5) 371-383, (2015).

5. M.K. Nock, J.M. Park, C.T. Finn, T.L. Deliberto, H.J. Dour, M.R. Banaji, Psychol. Sci. 21(4), 511-517 (2010).

6. K. Turvey, N. Pachler, Computers \& Education 146, (2020)

7. L. Darling-Hammond, J. Bransford (Eds.), Theories of learning and their roles in teaching, Preparing teachers for a changing world (Jossey-Bass, San Francisco, 2005).

8. P. Grossman, C.P. Dean, S.S. Kavanagh, Z. Herrmann, Phi Delta Kappan 100(7), 43-48 (2019)

9. M. Lampert, F. Graziani, The Elementary School Journal 109(5), 491-509 (2009).

10. J. Loughran, Teachers and Teaching 25(5), 523-535 (2019)

11. I. Backfisch, A. Lachner, K. Hash, F. Luz, K. Shater, Learning and Instruction 66, (2020)

12. K. Zierer, Oxford Review of Education 41(6), 782-798 (2015)

13. N. Hensley, Journal of Cleaner Production 243, (2020)

14. R.N. Dino, Psychology of Aesthetics, Creativity, and the Arts 9(2), 139-146 (2015)

15. T.A.W. Oddane, International Journal of Managing Projects in Business, 8(1), 3357 (2015).

16. M. Tang, C.H. Werner, Thinking Skills and Creativity 24, 268-278 (2017)

17. D. Schwartz, J. Bransford, D. Sears, Efficiency and innovation in transfer, In J. Mestre (Ed.), Transfer of learning from a modern multidisciplinary perspective (pp. 1-51). (Greenwich, CT: Information Age Publishing, 2005)

18. I. Männikkö, J. Husu, Teaching and Teacher Education 77, 126-137 (2019). 